\title{
EUS-guided gastrojejunostomy in the presence of ascites
}

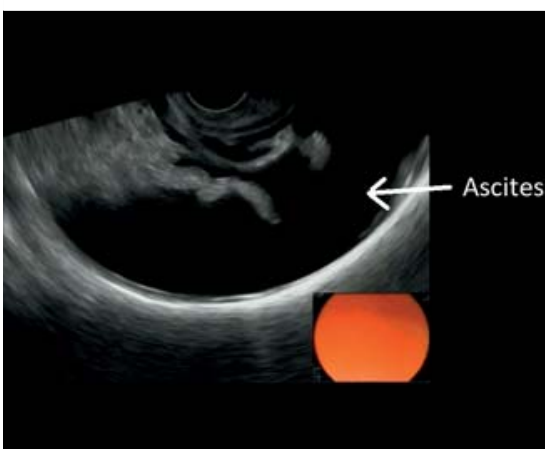

- Fig. 1 Endoscopic ultrasound image shows ascites in the peritoneal cavity.

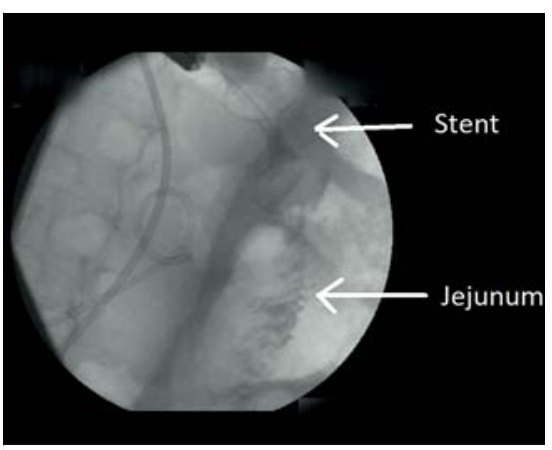

> Fig. 2 Fluoroscopic image shows the lumen-apposing metallic stent and the jejunal loop (arrows).

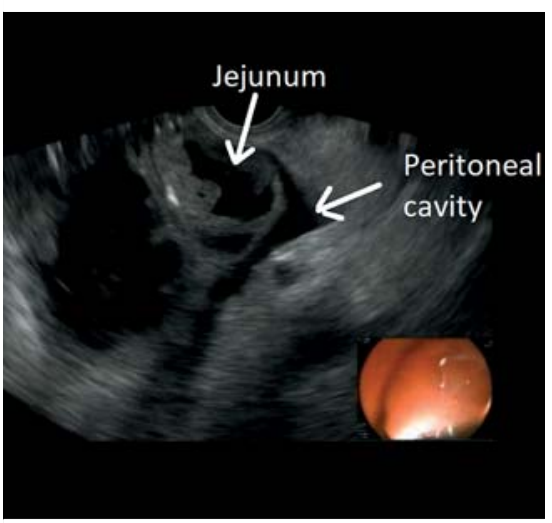

Fig. 3 Endoscopic ultrasound shows the distended jejunal loop and ascites in the peritoneal cavity (arrows).

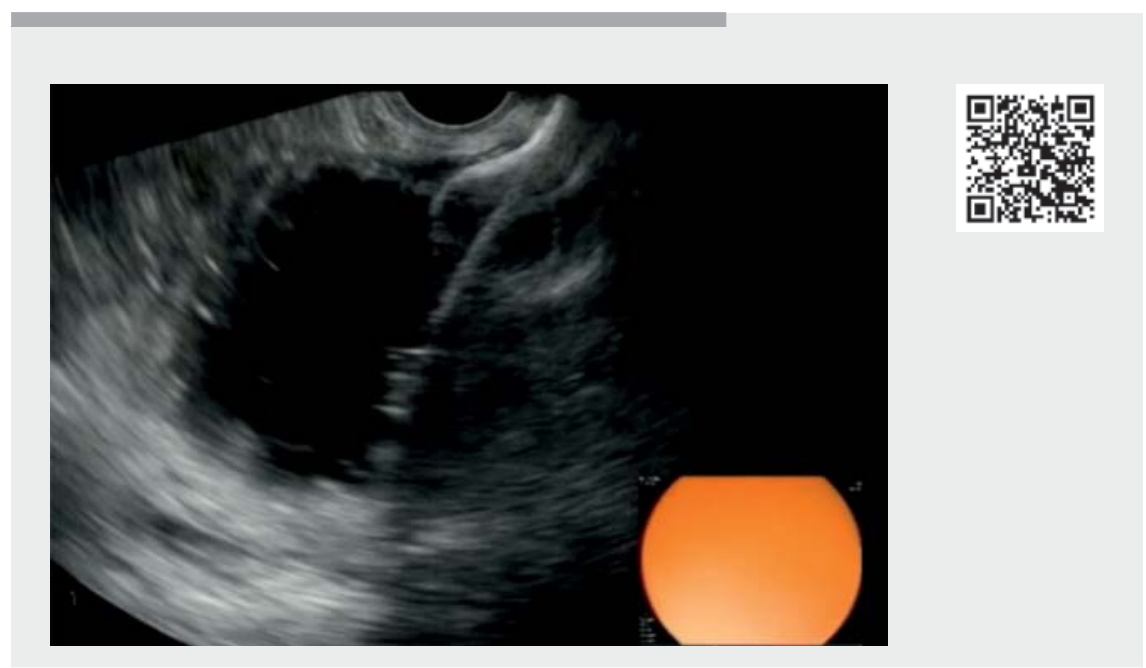

Video 1 Video demonstration of endoscopic ultrasound-guided gastrojejunostomy in the presence of ascites.

EUS-guided gastroenterostomy (EUS-GE) is a novel procedure to palliate malignant gastric outlet obstruction (GOO). Retrospective studies reported a higher rate of clinical success with EUS-GE compared to duodenal stenting [1]. The presence of ascites is often considered a contraindication for this procedure because of concern over the development of anastomotic dehiscence or peritonitis $[2,3]$.

Here, I describe a case of malignant GOO with ascites treated with EUS-GE to relieve GOO symptoms. A 59-year-old woman with locally advanced pancreatic head cancer presented with symptoms of GOO. An upper endoscopy revealed a severe non-traversable stricture in the second part of duodenum. The patient declined a surgical procedure and elected for EUS-GE for relief of GOO.

A 7-F nasobiliary tube was advanced over the guidewire to the jejunum to distend the jejunal loops with saline infusion. Then, a linear echoendoscope was advanced to the stomach. EUS unexpectedly revealed considerable ascites in the peritoneal cavity ( $\bullet$ Fig. $\mathbf{1}$ ). Since the ascitic fluid did not interpose between the gastric wall and the target jejunal loop, it was decided to continue the procedure. A $15 \times 10-\mathrm{mm}$ electrocautery-enhanced lumen-apposing metallic stent (AXIOS; Boston Scientific, Natick, Massachusetts, USA) was deployed between the stomach and a distended jejunal loop. The proper location of the stent was further confirmed with an injection of contrast material through the stent ( $\bullet$ Fig. 2, - Video 1). The GOO symptoms completely resolved after the procedure. The patient was then treated with periodic paracentesis for malignant ascites every two weeks and was subsequently referred for placement of an indwelling peritoneal catheter for ascites control. The patient remained well after 4 months of follow-up. To my knowledge, this is the first report of EUS-GE in the presence of ascites.

In conclusion, EUS-GE is feasible in the presence of considerable ascites. Care must be taken to distinguish fluid-filled jejunal loops from the peritoneal cavity filled with ascitic fluid ( $\bullet$ Fig. 3 ).

Endoscopy_UCTN_Code_CPL_1AH_2AD 


\section{Competing interests}

The authors declare that they have no conflict of interest.

The author

\section{Mehdi Mohamadnejad ${ }^{\circ}$}

Liver and Pancreaticobiliary Research Center, Digestive Disease Research Institute, Tehran University of Medical Sciences, Tehran, Iran

\section{Corresponding author}

Mehdi Mohamadnejad, MD, FASGE

Digestive Diseases Research Institute,

Shariati Hospital, North Kargar Ave., Tehran 1411713135, Iran

mehdi.nejad@gmail.com

\section{References}

[1] Ge PS, Young JY, Dong W et al. EUS-guided gastroenterostomy versus enteral stent placement for palliation of malignant gastric outlet obstruction. Surg Endosc 2019; 33: 3404-3411

[2] Tonozuka R, Tsuchiya T, Mukai S et al. Endoscopic ultrasonography-guided gastroenterostomy techniques for treatment of malignant gastric outlet obstruction. Clin Endosc 2020; 53: 510-518

[3] Khashab MA. EUS-guided gastroenterostomy vs duodenal stenting for the palliation of malignant gastric outlet obstruction. Gastroenterol Hepatol (NY) 2019; 15: $323-$ 325

Bibliography

Endoscopy 2022; 54: E540-E541

DOI 10.1055/a-1675-1761

ISSN 0013-726X

published online 15.11.2021

(c) 2021. Thieme. All rights reserved.

Georg Thieme Verlag KG, Rüdigerstraße 14,

70469 Stuttgart, Germany
ENDOSCOPY E-VIDEOS

https://eref.thieme.de/e-videos

回回 Endoscopy E-Videos is an open access online section, 回: reporting on interesting cases and new techniques in gastroenterological endoscopy. All papers include a high quality video and all contributions are freely accessible online. Processing charges apply (currently EUR 375), discounts and wavers acc. to HINARI are available.

This section has its own submission website at

https://mc.manuscriptcentral.com/e-videos 